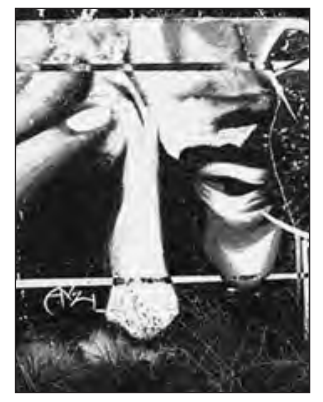

\title{
LA FILOSOFÍA DE LA EDUCACIÓN COMO SABER FILOSÓFICO
}

\author{
Lic. Mauricio Leyme, SDB
}

Universidad Politécnica Salesiana (Ecuador) 
Callias, si tuvieses por hijos dos potros o dos terneros, ¿no trataríamos de ponerles al cuidado del un hombre entendido, a quien pagásemos bien, para hacerlos tan buenos y hermosos, cuanto pudieran serlo, y les diera todas las buenas cualidades que debieran tener? ¿Y este hombre entendido, no debería ser un buen picador y un buen labrador? Y puesto que tienes por hijos hombres ¿Qué maestros has resueltos darles? ¿Qué hombre conocemos que sea capaz de dar lecciones sobre los deberes del hombre y del ciudadano?

Apología de Sócrates.

Reflexionar sobre el ser humano es reflexionar sobre el sentido de la existencia del mismo, el lugar ocupado por él en medio del cosmos; reflexionar sobre el hombre es preguntarse, encontrar y transformar su propia existencia; pero es, sobre todo, buscar su perfección, la cual se realiza en la realidad y en contacto con los otros seres humanos.

En el presente trabajo se presenta de manera breve, rasgos de las disciplinas más influyentes dentro de la educación, como es el caso de la biología, psicología, pedagogía y filosofía, siendo vital el unificarlas, pero surge la gran pregunta ¿cómo y en quien? la respuesta se la irá dando en el desarrollo del trabajo.

La biología tiene la gran virtud de hacer una gran explicación del ser humano y llegar a sus bases genéticas, pero esta descripción resulta incompleta al momento de comprender el hecho educativo pues lo hereditario no agota al ambiente o lo cultural; de hecho, una de las falencias de la biología es ignorar lo cultural.

Del mismo modo la psicología hace su aporte considerando el proceso de desarrollo del ser humano, ayudando de este modo a establecer diferencias en los procesos de aprendizaje y modos de aprendizaje, puesto que un niño que vive en la calle no poseerá las mismas facilidades de aprendizaje que uno que vive en un hogar 
bien conformado; su punto frágil está en quedarse en el análisis de los comportamientos y la historia personal que "condicionan" el proceso de aprendizaje.

El trabajo de la filosofía es arduo pues debería buscar el modo de enlazar las ciencias, teniendo en cuenta el que se busca ayudar a dar un sentido a la vida; es, sobre todo mostrar que la vida vale la pena ser vivida, en este sentido se da importancia a la operación pues es la parte perfectible del ser.

\section{La educación desde la Biología}

\subsection{El hombre como naturaleza}

Empecemos haciendo un recuento de lo que significa el término naturaleza desde su etimología: es aquel ámbito en el cual unas cosas nacen de otras inacabablemente; para Aristóteles es aquello que dispone de un principio interno del acontecer; en este sentido, la naturaleza, será cosmos que significa armonía.

Para Galileo la naturaleza es concebida como un conjunto de relaciones cognoscibles matemáticamente, entonces "la noción de la naturaleza se convierte en el correlato del conocimiento de las leyes que objetivan a los movimientos astrales como terrestres"1. Para Descartes la palabra naturaleza designa a la propia materia y no sólo a lo físico-químico, sino a cuanto es extenso. De estos modos de concebir la naturaleza vemos una clara oposición a la libertad, aunque es sensato cree que el ser humano no puede relacionarse a la naturaleza, pues el hombre es más que un pedazo de Physis a pesar de ser un ser de la naturaleza.

De esta manera el hombre no puede trascender la naturaleza, tal vez es la herencia que hemos recibido de los griegos, pues la naturaleza nos atrapa y nos quedamos prisioneros dentro de ella. 


\subsection{Insuficiencia de la Biología}

La especie humana es el resultado de filogenia ${ }^{2}$, pero cada individuo humano se explica desde su ontogénesis 3 ; en este sentido cualquier educando trae consigo conductas filogenéticas de millones de años pues la herencia se transmite a través de los genes ${ }^{4}$; la herencia genética de un individuo se objetiva en el cerebro huma$\mathrm{no}^{5}$, el cual otorga mayor importancia a las capacidades cognitivas que a las sensoriales y a las motoras, en cierta manera podemos decir que el proceso educativo pasa por el sistema nervioso (gracias a él, se pueden percibir los cambios en el medio interno y externo, reaccionar ante los estímulos y realizar todos los trabajos que necesita el organismo para funcionar) del educando y del educador.

En esta línea el hombre "es organismo psicobiológico que se intelige a través de la evolución, de la genética, del sistema nervioso y de la endocrinología"6.

La herencia asegura la acción, pero jamás determina qué acción; es decir, la cultura, la técnica ayudan al hombre a ser hombre; de este modo la biología influye en la herencia pero no totalmente en ambiente, pues lo biológico no descifra totalmente el hecho antropológico, además ninguna ciencia tiene derecho sobre la vida, pues la biología considera al hombre como un conjunto de células, sobre las cuales se puede intervenir.

\section{La educación desde la Pedagogía}

\subsection{Procesos educativos}

El proceso de educación forma parte de la antropología, por ende el ser humano no puede menos que educarse, pues la herencia biológica no nos dicta del todo 
lo que tenemos por hacer, se necesita también lo social y solo entrando en sociedad se entra en la historia; tengamos en cuenta lo siguiente: "el código genético es disponibilidad para la educación socializadora"7; de lo que se trata en educación, en cierto sentido, sería transmitir civilización creada por el grupo humano; el aprendizaje se lleva a cabo proporcionando informaciones precedentes de la civilización, buscando de este modo despertar actitudes y facilitar aptitudes.

La diversidad aparece al querer explicar el proceso educativo; han existido tres modelos: innatista, receptivo y apriorista.

- Receptivos: tiene como base el empirismo, considera que somos una página en blanco al momento de nuestro nacimiento, somos un contenedor que necesita ser llenado de información proveniente del exterior, se encuentran en esta línea el ruso Pavlov y el norteamericano Skiner.

- Innatista: tiene como base el racionalismo, se da privilegio a los conocimientos que viven con nosotros al nacer; aquí se encuentra Platón, San Agustín, Descartes; se sostiene asimismo que el desarrollo humano se encuentra en la influencia que ejerce el componente hereditario.

- Apriorista: arrancan de la filosofía de Kant, del cual vale tener en cuenta la siguiente afirmación:

"Si bien es cierto que todo nuestro conocimiento comienza con la experiencia, esto no prueba que todo él provenga de la experiencia...Podrá suceder que todo nuestro conocimiento...esté compuesto por lo que percibimos...y por aquello que pone nuestra capacidad de conocer" 8 ; con esto se quiere decir que existen dos formas de conocer: por el intelecto y por 
los sentidos, Kant une las dos maneras: "A través de los sentidos, los objetos nos son dados, mientras que a través del intelecto son pensados"9.

\subsection{Insuficiencia de la pedagogía}

Resulta difícil hacer una explicación de la complejidad humana sólo con el funcionamiento de la razón, o de la biología, pues no se deja de lado los contenidos morales y más aun la obligación moral. El saber, el hacer no son todo dentro de la educación; la sola razón no señala el sentido de la existencia del hombre.

Quizás la pedagogía se ha centrado demasiado en la relación enseñanza-aprendizaje, cayendo en el modelo receptivo; creer que el niño es "hoja en blanco"es dejar de lado la potencia de la inteligencia; en cierto sentido, los actos primeros no necesitan ser aprendidos; entonces a veces el proceso de aprendizaje del niño precede al proceso de enseñanza aprendizaje.

\section{La educación desde la Psicología}

Al llegar a este punto, es necesario tomar en cuenta los diferentes aportes que ha dado la psicología hacia la educación, mediante las orientaciones de diferentes escuelas psicológicas.

\subsection{Los Estructuralistas}

Sostenían que las complejas experiencias mentales eran en realidad estructuras edificadas con estados mentales simples. "Se basaban en la creencia de que la misión primera del psicólogo era explorar la estructura de la conciencia y formular las leyes de su formación"10; es decir, busca los elementos del acontecer psíquico para actuar 
sobre el comportamiento para luego modificarlo y comprenderlo.

\subsection{Los funcionalistas}

No estaban de acuerdo con el énfasis estructuralista sobre los estados mentales, éstos se preguntaban: ipara qué es la conciencia? ¿Cuál es su función? La pedagogía I46 cesos como el aprendizaje, la educación, el olvido, la memoria y las modificaciones de su comportamiento.

\subsection{Los psicoanalistas}

Nacen hincapié en el proceso mental del inconsciente, pues era allí donde debían buscarse las fuentes primarias de conflictos y desórdenes mentales; su mayor representante fue Freud.

\subsection{Los conductistas}

Sus técnicas de estudio son utilizadas en primer lugar con animales, pero luego son transferidas al estudio del proceder del hombre; se inclinan marcadamente hacia la fisiología y su mayor aporte para la psicología es el trabajo sobre los reflejos condicionados.

Podemos ver que el estudio acerca del ser humano se parcializa; en algunos se toma en cuenta el entorno; en otros no; en otro, se da prioridad a los sentidos, pero de una u otra forma se intenta dar un aporte, $y$ de hecho que la psicología ha ayudado a describir al ser humano, pero quizás sólo se ha quedado en la explicación de sus comportamientos los cuales se originan en el cerebro. 


\section{La filosofía de la educación}

Uno de los mayores problemas filosóficos y se podría decir pedagógicos por el hecho de centrar su reflexión sobre la persona humana y buscar la humanización de la misma, es el saber si la vida merece ser vivida, es decir, ¿qué sentido tiene nuestra vida? Sería ésta la línea de de la filosofía de la educación. "Ser educado significa estar ajustados a la vida, tener mayor capacidad de apreciar lo que es la vida, lo que ella puede ofrecer y lo que la persona, puede a su vez, ofrecer a la toda la sociedad"11.

La educación, tiene que llevar a la interiorización, a rescatar lo humano de la persona; es descender a lo íntimo de nuestro ser, pero la historia nos muestra que existe un gran inconveniente, la ciencia actual no nos permite hacer una reflexión acerca del sentido de la vida ${ }^{12}$, dado que cada vez deja de lado al hombre; pero quizás no sólo las ciencias sociales han caído en este error, tal vez las ciencias humanas también han sucumbido en la confusión de hablar sobre el hombre sin saber qué es el hombre o hacer una reflexión del ser humano sin el ser humano.

Del breve análisis realizado tanto a la biología, psicología y pedagogía, es necesario reflexionar sobre cuál debería ser el aporte de la filosofía de la educación dentro del proceso de humanización de la persona; esto equivale a hacernos la pregunta que reunía el ámbito científico, ético y religioso, ¿qué es el hombre?, se trata de una pregunta esencial dentro del desarrollo filosófico y pedagógico, pues no se puede hacer ninguna aplicación sobre aquello que no se conoce por los menos en sus dimensiones básicas.

No se trata solamente de una pregunta que conceptualiza o describe, sino que se trata de buscar unicidad, pues la persona es unidad sustancial, y de hacer una sín- 
tesis, de las disciplinas analizadas; se sigue entonces que la educación debe tener un sustento antropológico (con bases de la metafísica) pero no se debe menospreciar el valor de la ciencia, hay que dar entonces un sustento científico a la educación.

Veamos a continuación cuáles son los elementos constitutivos de lo específicamente humano.

\subsubsection{Capacidad intelectiva}

Vendría a ser la facultad humana para penetrar en la realidad, llevándonos al conocimiento de la verdad; nos ayuda a situarnos, pero el "el acto de intelección no es tan solo una actividad mental, sino también un factor constitutivo en el conocimiento humano"14, el acto de intelección organiza y a su vez da una aprehensión de relaciones y significados; en síntesis, el acto de intelección es un factor constitutivo del conocimiento humano.

\subsubsection{Libertad}

Es uno de los valores más importantes dentro de la formación de la persona, la comprensión inadecuada de la libertad hace de la persona un ser supremo e independiente; de esto resulta que es necesario realizar una visión metafísica del hombre, como ya lo mencionamos anteriormente, y de las cosas. La libertad reside propiamente en la voluntad, pero sin conocimiento de la verdad no hay libertad, en síntesis la libertad debería tener en criterio de autodeterminación, pues sujeto es el que proyecta y define sus acciones.

En conclusión, si la libertad reside en la voluntad, que es por naturaleza un apetito obediente de la razón, síguese que la libertad misma ha de versar, lo mismo que la voluntad, acerca del bien, conforme con la razón. 
La libertad se ejercita en las relaciones con los seres humanos:

"La persona se manifiesta esencialmente como un ser único irrepetible, dotado de interioridad -autoconciencia y libertad-, y destinado a la comunión, es decir, es un sujeto que existe corporalmente con otros en el mundo, para realizarse con ellos en la historia... comprometiéndose libremente frente a los valores, frente a las demás personas y sobre todo frente a Dios"15.

\subsubsection{Trascendencia}

La persona, mediante su inteligencia, puede salir de sí misma y superar los niveles infrahumanos, es decir, superar la naturaleza pero no para despreciarlos o considerarse ajena a ellos; los trasciende, pero para darles mayor valor y sentido, en cierto sentido la trascendencia se debe tratar en referencia al hombre, pues es un nivel íntimamente vivido. Se hace necesario pues la exigencia de lo Trascendente, pues se siente una insatisfacción, la insatisfacción implica la ausencia de algo o Alguien, pero que es exterior a mí, aunque pueda asimilarlo y hacerlo mío.

La exigencia de Dios no es otra cosa sino el auténtico rostro de la exigencia de la trascendencia; en síntesis la educación nos debe ayudar a trascender al ser Trascendente, pues cada ser humano lleva dentro de sí el deseo hacia el ser Supremo, de allí que una educación que no proponga al Trascendente, es una educación incompleta.

\subsection{El fin de la educación}

"Cuando se inquiere la finalidad de la educación, hay que preguntar esencial y primordialmente por el 
fin de la educación misma"16; puesto que la reflexión no va desapegada del hombre se infiere que la educación debería estar unida hacia el fin del hombre; dicho de otra manera a la "perfección del hombre"; o sea, a la posesión de sí mismo. Pero la perfección del hombre, tal como lo señala Santo Tomás, es doble, pues la primera es perfección en cuanto la cosa en su sustancia es perfecta, y la segunda es el fin lo que se va construyendo; es decir, la persona es perfecta pero también es perfectible, la perfección segunda solamente se consigue por medio de la operación, pues está unida a lo más intimo de la sustancia: Operari sequitur esse et modus operando modum essendi17, el hombre operando se perfecciona porque actualiza sus potencias. Éste debería ser uno de los fines de la educación: actualizar o formalizar las potencias del que realiza el acto del aprendizaje, pero no sólo eso sino también que se debe ordenar al buen ejercicio de las operaciones, pues hay operaciones que en vez de perfeccionar al hombre lo van destruyendo; no hay que dejar de lado que las operaciones incluyen la racionalización de la experiencia; entonces, el otro fin de la educación sería buscar los medios para que las operaciones sean humanas.

La actividad educativa tiene por finalidad la formación cristiana del hombre o, para ser más exactos, la formación del hombre cristiano, es decir, el fin de la educación es cooperar con la gracia divina para formar al verdadero y perfecto cristiano.

Podemos decir también que una propuesta educativa sin un ser trascendente es incompleta, pues es por naturaleza que el ser humano tiene el deseo de un ser trascendente en el cual se encuentran todas las perfecciones y sobre todo en quien está el bien supremo, pues ningún ser trascendente va en contra de la dignidad del ser humano; al contrario, lo ayuda, para dignificarse y humanizarse. 
Para llegar a dicho ser se requiere de interioridad; en este sentido, la filosofía de la educación está llamada a despertar al ser humano, sobre todo en sus aspectos esenciales de la vida; no se trata de caer en un espiritualismo, sino de alcanzar una armonía con el cosmos y una integración con los demás seres de la naturaleza.

\section{Conclusiones}

- Tanto la biología, la psicología, la pedagogía son ciencias que han aportado en el proceso educativo; sin embrago, a pesar de haberlas analizado separadamente en el acto educativo se encuentran unidas en el ser humano, pues es él quien realiza el hecho educativo.

- La concepción enseñanza aprendizaje ha aportado en el desarrollo educativo, pero parece que sería tiempo de cambiarlo; hay que hacer un giro copernicano en la educación, deberíamos pasar a comprensión y explicación, sería rescatar la disponibilidad de la mente para el aprendizaje.

- El fin de la educación es la perfección de la "perfección segunda", esto equivale a decir: la educación es la encargada de perfección al ser humano. Entonces, no sólo de trata de llenar vacíos en el intelecto o actualizar conocimientos pasados, sino de humanizar la vida del ser humano.

- El personalismo nos ayuda en dos sentido: llegar hacia el ser trascendente lo cual provoca fidelidad y compromiso, pues acercarse el misterio es salir de las esferas del "espacio tiempo"; pero se lo realiza dentro del espacio y el tiempo; el segundo sentido es que recupera el valor central, la persona como la que ejecuta el proceso de operación para llegar a la humanización. 


\section{Notas:}

1 FULLAT, Octavi, Antropología filosófica de la Educación, Pág. 33.

2 Sucesión de formas orgánicas emparentadas secuencialmente por relaciones reproductivas. Y los cambios experimentados a lo largo de la filogenia constituyen el cambio filogenético o evolutivo. MATURANA, Humberto, El Árbol del conocimiento, Pág. 69.

3 La historia de cambio estructural de una unidad sin que ésta pierda su organización. Ibíd. Pág. 49.

4 Cf. MARCUS, Gary, El nacimiento de la mente, Pág. 17.

5 Para una explicación más detallada y profunda puede verse en AYLLON, José Ramón, Filosofía Mínima, Págs. 122124.

6 FUllat, Octavi, Op. Cit, Pág. 39.

7 Cf. MARCUS, Gary, Op. Cit, Cap. II.

8 FUllat, Octavi, Op. Cit, Pág. 95.

9 REALE, Giovanni, Historia del pensamiento filosófico $y$ científico, Pág. 737.

10 SPERLING, Abraham, Psicología simplificada, Pág. 21.

11 MATTALDI, Luis María, Juan Pablo II, Cultura y Evangelización I, Pág. 174.

12 Para profundizar puede verse la obra de GRONDIN, Jean, Del sentido de la vida,

14 LONERGAN, Bernard, Inight, Pág. 12.

15 GASTALDI, Ítalo, El hombre un misterio, Pág. 169

16 GONZÁLES, Angel, Filosofía de la Educación, Pág. 137.,

17 El obrar sigue al ser y el modo de obrar al modo de ser. 